\title{
Una aproximación hispánica a Debora Barón
}

\author{
Por Encarnación Varela
}

Hacia fines del siglo XIX la vida judra tradicional, precaria y a la vez milagrosamente sostenida durante generaciones bajo el esquema de "sociedad cerrada", parece llegar a su término.

Como en todos los eventos de la historia judía en que se marca de manera totalmente subjetiva y convencional el fin de una época y el comienzo de otra, son utopias colectivas las que arrastran grandes masas de población de un continente a otro (emigración a América de un tercio de la población judía mundial), de un mesianismo milenario y ritualizado a un mesianismo moderno, laico, estatista y sin Dios (el Sionismo realizador), y a la revolución inmediata realizada por el voluntarismo de unos pocos que aspiran a conseguir la solidaridad y el reconocimiento de muchos y crear el paraíso internacionalista.

Estas tres utopías, en el sentido que les da el sociólogo Karl Manhein de fuerza de avance o "imaginación social", se harán realidad parcial y eclécticamente -como todos los eventos históricos- en los umbrales del siglo $\mathrm{XX}$, y harán avanzar al pueblo judío hacia la modernidad dándole la configuración y el aspecto que más o menos conserva hasta la fecha en las tres comunidades más grandes del mundo, cuantitativa y cualitativamente consideradas: Estados Unidos, la URSS e Israel.

Pero este avance y paso en el tiempo y el espacio supone un trauma para los más sensibles a la memoria colectiva y una destrucción del individuo judio portador de valores y retroalimentado por toda la comunidad y el orden atávico de vida. Implica la destrucción del tejido milenario de tradiciones, a veces crueles y absurdas, pero casi siempre compensatorias por las ventajas y el clima íntimo de la "sociedad cerrada". Este tejido social no será fácilmente reemplazado, $y$ con rebeldía vuelve a aparecer en múltiples formas y conductas en la moderna Israel.

Entre los más sensibles portavoces de la memoria colectiva de esa época de transición se encuentra la escritora Débora Barón (1887-1956). Nacida 
en Ozdah, uno de tantos pueblecitos perdidos en las nieves de la Rusia Blanca, le toca vivir el drama de la transición de épocas y compartir el dudoso pan de todas las utopias nombradas anteriormente, cuando su mundo subjetivo y su arsenal de imágenes y asociaciones está enteramente copado por la figura de su padre, rabino del pueblo que mantenía en su casa el Bet Qahal (Casa del Pueblo y Tribunal Rabinico).

Era un mundo armónico que respondía a un orden previamente establecido y avalado por la Historia y el consenso social, lo que no lo eximía de ser a veces cruel, jerárquico y machista.

Esos colores, tanto axiológicos como descriptivos, compondrán la rica paleta de Débora Barón.

Al amor por el pasado idílico, jerárquico y superprotector, al amor por la imagen del padre rabino, que aparece como numen de su comunidad perdida y como persistente alter ego de su obra y tal vez de su personalidad se une el rechazo de formas de vida que ya le parecen caducas y contra las que toda su generación se rebela.

Una de las formas de rebelión es la 'Aliyah (ascenso, inmigración a Eres Israel) por la que opta una pequeña parte de la élite intelectual judía, y entre ellos, la escritora, que parte hacia Yaffo en 1911.

Eran los días de la ya mitológica Segunda 'Aliyah, la de los pioneros, sofnadores y luchadores solitarios como Brener, A. D. Gordon Agnon, Berl Katzenelson, Raquel, Ben Gurión y un largo etcétera.

Eran también los dias finales del corrompido Imperio Turco, de las conspiraciones probritánicas, del independentismo absoluto, del primer regionalismo mediterráneo y palestino. (M. Smilansky, Aronson, etc.), y del internacionalismo que en Yaffo, Jerusalén y Raml hablabla en Yiddis, tremolaba banderas rojas y pretendía redimir a árabes y judíos a un mismo tiempo por medio de fórmulas "cientificas".

Ya en Israel se instala en la incipiente y futurista ciudad de Tel Aviv, recostada entre el mar Mediterráneo, la vieja "kasbah" árabe de Yaffo y los naranjales de Petaj Tikva (Portal de la Esperanza), primera colonia agricola moderna construida por pioneros e hijos rebeldes del asentamiento ultraortodoxo de Jerusalén.

De Yaffo vienen las llamadas del muezin a la oración de la Media Luna; también llegan aquí barcos cargados de nuevos colonos idealistas, y parten a Rusia y a América barcos cargados de derrotados, febriles y hambreados por la realidad del país-utopía. De Yaffo vienen caravanas de camellos y asnos cargando cemento, piedras $y$ arena, $y$ durante todo el día no cesan los martillos y el fragor de las máquinas que construyen la ciudad de Tel Aviv, blanca novia mediterránea y futurista prometida al hombre nuevo que tienen que engendrar los hebreos -cada 2.000 anos engendran uno-. Ese hombre nuevo ya no exige virginidad a su novia; sí le exige vigor, experiencia, iconoclastia y corta memoria. 
Es cuando Shlonsky canta al "Nuevo Pacto" del "Nuevo Génesis", y Alterman en términos casi eróticos dice: "Te queremos, patria mía / echada y surcada de arados. / Te vestiremos con vestido de hormigón y de cemento...".

Por entonces se casa nuestra escritora con Yosef Aharonowitch, activista de la SegundasiAliyah-y-del Sionisma Obrera, y editor del periodico y de la editorial Hapo el Hasair ("El Joven Obrero", Partido Socialdemócrata de Eres Israel fundado pör Berl Katzenelson). Eso le permite colaborar durante diez largos años con el periódico, publicar sus primeros cuentos y estar activamente ligada a la vida del Sionismo Constructivista.

Pero es asombroso que en este clima proyectado hacia el futuro donde "recordar con ira" es la norma, Débora Barón se niegue a olvidar, y así se erige en la fina estilista del pasado jud fo y del hogar irrecuperable. Por esa época escribe también Y. D. Berkowich, de intachable prosa hebrea, yerno y fiel traductor de Shalom Aleijem. También él intuye que la nueva creación de un Estado judío no es más que apiñar junto al mar a un gran campamento de refugiados.

Pero Débora Barón se queda a mitad de camino entre Méndele y Bashevis Singer. Al decir que se queda a mitad de camino no pretendemos mediatizarla ni disminuir su mérito, sino colocarla en uno de los vértices del triángulo de la vida judía y sus grandes críticos, en realidad de sus detractoresamantes y verdugos.

Méndele es puro conocimiento, sarcasmo y crítica, último coletazo de la Haskalá (Iluminismo) regeneracionista. Bashevis Singer, contemporáneo, radicado en Nueva York, escribe en Yiddiš y se traduce al inglés, folkloriza su mercancia, la erotiza, la exorciza, la demoniza, es consciente de que "escribe en una lengua muerta sobre un pueblo de fantasmas" -según sus propias palabras al recibir el Premio Nobel.

En Débora Barón encontramos la dimensión de la ternura y algo más, hay una necesidad de cantar y prologar lo que ya va siendo epílogo.

Encontramos varias líneas rectoras en la obra de esta poetisa en prosa del pasado inmediato judio que perecerá luego en las llamas:

1.-La identificación con la Tradición como Ethos colectivo, con aquellos ancestrales valores de la Ley judía que fueron operativos y dieron luz y calor de fe a tantas generaciones. Pero aún rescata el precio del valor del individuo, generalmente mujer, que rinde y sojuzga sus propias apetencias y deseos ante esa Ley, que en realidad es consenso de la comunidad. Aquí hay tema para los freudianos, gustosos de buscar el papel de la cultura, el inconsciente y la neurosis, y tal vez ( „nuevamente Freud!) la riqueza espiritual y la entereza de su padre, el rabino Shabtay Eliezer Barón, frente a los balbuceantes y frágiles personajes del nuevo ethos palestino que surge en Tel Aviv, como de la nada. 
2.--El Hombre contra su Destino, el viejo tema existencial del sufrimiento gratuito, del hombre a quien parecen caerle todos los anatemas del cielo y de la gente sin que se sepa claramente el porqué.

En esa línea se enmarca el cuento que hemos elegido y traducido, pero a diferencia del Job bíblico -que ya se sabe que no es judío, pero que inaugura la vieja costumbre judía de inquirir a lo Insondable- este hacedor de ladrillos que mientras vive "enmudece como Arón" y que muere sin un quejido, encuentra un consuelo póstumo ( iflaco consuelo!) y deja un mensaje que al menos no es tan forzado como el del Job de la Escritura: "No sabía que el destino del ladrillero es el destino de la mayoría de seres que habitan la tierra: esfuerzos, fatigas y envilecimiento en el barro, y todo esto en una existencia de sufrimientos que los va envolviendo poco a poco como las ramas del árbol prodigioso que llaman Arbol de la Muerte. Y sin embargo esto es bueno para el que dejó al menos algo que pudiera emanar un poco de luz y calor para los que vienen detrás."

Las gentes del lugar tomaron sus ladrillos para hacer hornos y chimeneas; sin saberlo las pobres gentes, egoístas y atareadas como todos los mortales, fueron más que los amigos teólogos de Job, se quedaron en ese sitio, habitaron sus casas, dieron sentido a su muerte. ¿Y quién de nosotros no está inmerso en el barro hasta la cintura? -pregunta Débora Barón, preguntamos nosotros, recogiendo sus ladrillos.

3.-El conflicto entre el hombre judio y la Legislación judia, que culminará con la dispersión hacia los cuatro vientos de la Historia, con el total abandono del hogar paterno, con el imposible retorno y la memoria necesaria.

4. - La embozada lucha de clases en el seno de la comunidad judia. El tema es viejo, y ya desde los días de los Profetas se le viene tratando; pero por primera vez y por manos de esta frágil y sensible mujer cargada de asociaciones sacrales y litúrgicas, adivinamos "el clamor del pueblo que subió desde la servidumbre de Egipto", sólo que ahora no aparece un Moisés; hay una protesta muda como en otra de sus obras, $\mathrm{Ba}$ 'al Ha-tokahot (El Sermoneador), o un activismo inútil y casi suicida, pero mesiánico aun desde su bolchevismo, como en Garinim (Semillas). El credo socialdemócrata de la autora y de su esposo les hace creer que Eres Israel renovada será la panacea para todos los conflictos sociales. Pero ese mismo credo les hace ignorar el camino para conseguirlo - de ser posible conseguirlo.

5.--La identificación con la mujer. En Débora Barón esa identificación surge de la natural identificación con el débil, pero podemos llamarla con justicia escritora feminista, pues de la mera defensa del infeliz pasa a una fina captación del alma femenina, sus conflictos con la Ley, escrita por y para hombres, el desamor que espera amor sin desesperar, la vida en gracia y casi siempre la gracia de la muerte, y en última instancia una 
agria crítica a la falocracia semitica, al poder omnipotente del hombre, del Dios que es masculino porque no puede ser humano, y que por eso inspira la Halakah (Ley Rabinica).

Débora Barón es una crítica sutil de la cultura judía tal como se presentaba hacia fines del siglo XIX.

Hoy semitas van quedando pocos, pues el Medio Oriente es un Babel que confunde lenguas y razas, pero sospechamos que, sin Kratos, el falo sigue flotando en ambas riberas del Mediterráneo, $\tan$ nuestro y $\tan$ borracho de sol y represiones.

Por todo esto Débora Barón es una escritora feminista, profundamente femenina, profundamente judía, trabajosamente israelí.

Muere en 1956, construido el Estado Judfo y ahíto de guerras y asedios. Es trabajosamente israeli como el ladrillero es trabajosamente un ser a quien el dolor mantiene humano.

No hemos escogido su mejor cuento por motivos técnicos y de espacio, sólo nos hemos limitado a calentarnos a la luz y al calor de sus ladrillos.

\section{EL HACEDOR DE LADRILLOS}

\section{Débora Barón}

Ladrillos de arcilla para los hornos solía hacer en el pueblo de Ana el ladrillero Libke, diminutivo con el que la pequeña le llamaba, parece que por su miserable aspecto, ya que se trataba de un hombre adulto y tampoco era pequeño de estatura.

A través de la ventana de la cocina del Bet Qahal (1) podfa verle Ana cuando caminaba descalzo y medio desnudo junto al pozo y cuando trabajaba en la arcilla ajena, porque Libke era solamente un asalariado, la alfarería era de Yehiel-Ber, duef̃o de los hornos.

Al igual que sus antepasados en Egipto Libke amasaba y pisoteaba en la arcilla, y levantaba con gran esfuerzo el molde, mientras también él suspiraba en su interior: "¡Lo mismo que ellos en aquel tiempo!", pues padecía reumatismo y los bruscos movimientos le causaban dolor.

A mediodía aparecía allí a veces su patrón Yehiel-Ber, hombre despótico bajo cuyo rico traje Ana se imaginaba ver una especie de látigo. Con pasos acelerados atravesaba la alfarería - en su casa, por detrás de cuya cerca se oía ya el alegre tintineo de las campanillas de plata que anunciaban la

(1) Bet Qahal: Casa del pueblo, lugar de reunión de la Comunidad. 
preparación de la mesa para el almuerzo-, miraba por debajo del cobertizo hacia el centro, al pozo, y caminaba hacia él mientras lanzaba contra su asalariado palabras de reconverción -seguramente porque no habra hecho una suficiente cantidad de ladrillos-. Y aquél, con su probreza de espiritu, sólo acertaba a encogerse, vacilaba por momentos en medio de la arcilla blanda, y al inclinarse para levantar el molde lo veía Ana como si estuviera pegado a la tierra.

-Se inclina bajo el peso de sus angustias-, se compadecía de él la mujer del rabino, la madre de Ana, al verle así. Pues la verdad es que en un corto espacio de tiempo se le habfan muerto su mujer y sus dos hijos. Los muchachos, Abramillo y Jonás, eran los dos de carácter agradable, y maravillaban a su maestro Levi Yishaq por la agudeza de su inteligencia. Y en un solo día le fueron arrebatados.

Era un frío día de invierno, y cuando Libke salió con sus compañeros a la blancura de la nieve se sintió como encandilado. No elevó ninguna lamentación ni dejó escuchar un gemido... como si no oyera nada. Escuchaba cuando le recordaban a la niña Mirel, su hija única, a la que en el tiempo de la enfermedad de la madre se llevaron los parientes a su casa, al pueblo de Kaminkah.

-Es una prueba semejante al "Enmudeció Arón" (2), le explicó el maestro Leví Yishaq, que estaba entre los que consolaban al afligido.

A través de las rejas de la valla habfa visto Ana la mirada del hombre al interior del pozo abierto cuando éste llegó por primera vez, en la primavera, a su lugar de trabajo. El jardf́n de Leví Yishaq que estaba enfrente ya tenía preparada en esta época su cerca, y con ojos asombrados miraba él los surcos, que mostraban, como siempre en esta estación, su cobertura verde. $Y$ he aqui que los alumnos salfan del otro lado, del heder (3); entonces él alargaba su cuello, se detenía y los contemplaba un momento con una mirada en la que se adivinaba algo de esperanza.

En su cuarto, en la barraca, estaba la cama de los muchachos sin extender, sobre la mesa aparecian tirados los libros escolares, en los que por la noche, en sus pesadillas, ofa el hombre a veces como un susurro que viniera del pasar las páginas -en el Bet Qahal, a la hora del hatabat halom (4), él contaba esto-. Se despertaba y se daba la vuelta vigilante sobre el jergón, en el cual le pareća flotar en medio de un negro vacío.

Cuando despuntaba por fin la mañana se levantaba y salfa a pisotear en la arcilla con sus pies doloridos, porque lo cierto es que tenía que pagar su deuda en la tienda de comestibles, y comprar sal, cebolla y un trozo de queso para añadir al pan.

(2) Alusión bíblica a la prue ba que sufrió Aarón al serle arrebatados sus hijos (Lv 10,3).

(3) Escuela básica de enseñanza rabínica.

(4) Oración contra los malos sueños. 
Ana, en momentos de desaliento de su vida, se sentra unida a este hombre. No estaba sola.

Ahí estaba; realmente era un hombre colmado de amargura, y con todo, se levantaba cada mañana y clamaba con temor y devoción:

"Te doy gracias a Ti, Rey vivo y existente,

porque me has restaurado y has derramado misericoria sobre mí..."

A mediados del verano trajeron del pueblo de Kaminkah a la pequeña Mirel, de 11 años. Su pariente la llevó a la alfarería con su hatillo y se apresuró a volver a la plaza del mercado, donde habra quedado su carro sin vigilancia.

El padre se quedó sorprendido cuando apareció la niña, y se apoderó de él una especie de locura. Parecía que solamente ahora, ante la aparición de ella, comprendía todo lo que le había ocurrido. Y soltando el molde alzó sus manos, volvió a bajarlas y ocultó en ellas su rostro. Entonces lloró.

Las mujeres que se habían reunido y que llegaban allí le decian que pecaba contra Dios:

$-i$ Es que no ves lo que tienes aquí? -Exclamaban-. Pues la niña era verdaderamente admirable, deliciosa. Su cabello era dorado, y su mirada triste y ardiente; tal vez se le conmovia el corazón por su padre.

Algunas vecinas deseaban ayudar al hombre en el recibimiento de la recién llegada, pero ella, después de despojarse de sus hermosos vestidos, se paseó dos o tres veces con los pies descalzos por el enlosado de arcilla. Habia vuelto a casa.

De lo que habia sido un vestido viejo de su madre se hizo un delantal, se ató un pañuelo a la cabeza, y no había pasado mucho tiempo cuando la barraca abandonada tomó de nuevo el aspecto de un hogar. Las almohadas de los jergones fueron recogidas y ordenadas en la cabecera de la cama, los estantes vacíos se llenaros de ollas y platos limpios, y al final del día el recinto brillaba con el fuego de la chimenea, donde la muchacha cocinaba la cena -la sopa de granos de cereal o de espigas de avena, preparada al estilo de su madre.

En la casa de sus parientes, en Kaminkah, un profesor particular le habia enseñado a leer y escribir, y ahora, al anochecer, se sentaba a la mesa a la luz de la lámpara y llenaba los cuadernos vacíos de sus hermanos de líneas de una escritura perfecta, o bien, buscando algo para ejercitarse en la lectura, hojeaba los libros escolares.

El padre, sobre el jergón de enfrente contenía su respiración para escuchar este susurro del pasar las hojas, y cuando se dormía sentía que se habia llenado el vacio de su alrededor, y que la habitación se inundaba totalmente de luz.

Pero todo esto pasó pronto y desapareció como un sueño. Una vez, en un día tórrido por la tarde, marchó la chica con sus amigas al río a bañarse y ya no volvió. Temiendo que pasaran por alli los labradores se retiró a un 
lugar en el que sólo habra aguas estancadas. Los que estaban en el puente la vieron hundirse en las profundidades del abismo, pero cuando llegaron hasta allí no encontraron más que algunas burbujas en la superficie del agua y unas cuantas cañas de junco que habra recogido antes en un campo de la pradera.

El padre, lavado ya después del trabajo, estaba a punto de salir hacia la sinagoga para la oración cuando vio a Petak, el muchacho de los pastores, empujado hasta su patio por los que vivfan en la llanura, y reconoció en sus manos la tela del vestido de su hija.

Después fueron apareciendo los demás desde la callejuela de la Comunidad, desde la plaza del mercado, desde la calle larga... La gente acude al olor de la desgracia ajena -cuando están ellos a salvo- como al olor del humo del incendio. Se apresuran a llegar al lugar del suceso; se conmueven sin duda por lo que ven, pero al mismo tiempo, como ante un edificio en llamas, también se calientan un poco con su luz.

Todavía no habia terminado el hombre su año de luto cuando en el Qadiš (5) la incluía también a ella, a su niña.

A pesar de todo iba y venía de acá para allá en la alfareria, aunque ahora sin seguridad en sus pasos, como si se encontrara sobre la superficie de un río. Hasta que un día, al ponerse en pie apoyándose en el carro cargado de ladrillos que se tambaleaba, tropezó y se cayó para no levantarse más.

Por la noche, al oscurecer el día de la Gran Feria, murió, y los hombres se apresuraron a sacarlo de madrugada, pues les preocupaba que al pasar por el mercado se les juntara con los carros, y además tenfan prisa por volver el uno a su taller y el otro a su tienda.

Recordaba Ana el aspecto de la barraca cuando iba a verla después de esto, su brillo anterior descubierto por la ventana, frente a la alfarería, silenciosa; ahora reinaba allí el vacío, un vacío negro como aquél sobre el que se hablaba en el Bet Qahal a la hora del hatabat halom. Todo esto ocurría frente a la plazoleta del mercado con sus tumultos y el bullicio de las voces de los feriantes... eso que escuchaba es lo que llaman "vida"...

Aún no había pasado un mes cuando la barraca fue alquilada a otros inquilinos, y también la alfareria habfa sido evacuada, porque su dueño trasladó el cobertizo con los útiles de trabajo a otro lugar.

Los vecinos de la calle trajeron cada uno su montón de basura y taparon el pozo, y después esparcieron por encima un poco de arena. Y Ana, con un sentimiento cuyo nombre no conocía, examinaba los cambios en

(5) Oración judía por los difuntos. 
medio de este hueco vacio en el que le parecía escuchar aún el eco de los suspiros del hombre, y del que no quedaba ya ningún recuerdo, excepto unos pocos ladrillos que los habitantes del lugar tomaron para arreglar los fogones y las chimeneas.

Todavía se apenaba ella cada año junto a su madre. No sabía que el destino del ladrillero es el destino de la mayoría de los seres humanos que habitan la tierra: esfuerzos, fatigas y envilecimiento en el barro, y todo esto en una existencia de sufrimiento que los va envolviendo poco a poco como las ramas del árbol prodigioso que llaman Arbol de la Muerte. Y, sin embargo, esto es bueno para el que dejó al menos algo que pudiera emanar un poco de luz y calor para los que vienen detrás.

\section{BIBLIOGRAFIA}

BARON, Débora, Yalqut Sipurim, Tel Aviv, 1971.

GOLDBERG, Lea, Parsiot liborzh Ba'ron, "Orlogin"II, 16-32.

KASENELSON-SAZAR, R., 'al'adamat ha-ihrit, Jerusalem, 1966.

FIKMAN, Y., Bene dor, Tel Aviv, 1952, 254-287.

ZMORA, I., Sifrut 'al parsat dorot III, Tel Aviv, 1950, $113,30$. 